\title{
BMJ Open Is neighbourhood income inequality associated with maternal mental health? A longitudinal analysis of pregnant and new mothers living in Calgary, Alberta
}

\author{
Samuel AJ Lowe (D) , ${ }^{1}$ Sheila McDonald (D) ," Ambikaipakan Senthilselvan (D) ,1 \\ Candace IJ Nykiforuk (D) , ${ }^{1}$ Radha Chari, ${ }^{3}$ Roman Pabayo (D) ${ }^{1}$
}

To cite: Lowe SAJ, McDonald S, Senthilselvan $A$, et al. Is neighbourhood income inequality associated with maternal mental health? A longitudinal analysis of pregnant and new mothers living in Calgary, Alberta. BMJ Open 2021;11:e049220. doi:10.1136/ bmjopen-2021-049220

- Prepublication history for this paper is available online To view these files, please visit the journal online (http://dx.doi. org/10.1136/bmjopen-2021 049220).

Received 19 January 2021 Accepted 19 November 2021

A) Check for updates

C Author(s) (or their employer(s)) 2021. Re-use permitted under CC BY-NC. No commercial re-use. See rights and permissions. Published by BMJ.

${ }^{1}$ School of Public Health, University of Alberta, Edmonton, Alberta, Canada

${ }^{2}$ Cumming School of Medicine, Department of Community Health Sciences, University of Calgary, Calgary, Alberta, Canada

${ }^{3}$ Faculty of Medicine \& Dentistry, University of Alberta, Edmonton, Alberta, Canada

Correspondence to

Mr Samuel AJ Lowe;

salowe@ualberta.ca

\section{ABSTRACT}

Objectives Rising income inequality is a potential risk factor for poor mental health, however, little work has investigated this link among mothers. Our goal was to determine if neighbourhood-level income inequality was associated with maternal mental health over time.

Design Secondary data analysis using a retrospective cohort study design.

Setting and participants Data from the All Our Families (AOF) ongoing cohort study in the city of Calgary (Canada) were used, with our sample including 2461 mothers. Participant data were collected at six time points from 2008 to 2014 , corresponding to $<25$ weeks of pregnancy to 3 years post partum. AOF mothers were linked to 196 geographically defined Calgary neighbourhoods using postal code information and 2006 Canada Census data.

Main outcome measures Anxiety symptoms measured using the Spielberger State Anxiety Inventory, and depressive symptoms measured using the Edinburgh Postnatal Depression Scale and the Centre for Epidemiologic Studies-Depression Scale.

Results Multilevel regression modelling was used to quantify the associations between neighbourhood-level income inequality and continuous mental health symptoms over time. For anxiety symptoms, the interaction term between neighbourhood Gini and time was significant ( $\beta=0.0017,95 \% \mathrm{Cl}=0.00049$ to $0.0028, p=0.005$ ), indicating an excess rate of change over time. Specifically, a SD increase in Gini (Z-score) was associated with an average monthly rate increase in anxiety symptom scores of $1.001 \%$ per month. While depressive symptom scores followed similar longitudinal trajectories across levels of income inequality, we did not find significant evidence for an association between inequality and depressive symptoms. There was no evidence of a cross-level interaction between inequality and household income on either outcome.

Conclusion Income inequality within neighbourhoods appears to adversely impact the mental health trajectories of pregnant and new mothers. Further research is needed to understand the mechanisms that explain this relationship, and how interventions to reduce income inequality could benefit mental health.
Strengths and limitations of this study

- The study used longitudinal data, which encompassed a 6 -year period and included six distinct data collection time points.

- The study considered income inequality at the neighbourhood level, which provided a broader range of inequality than previous studies at the provincial level.

- The dataset did not include information on participant residence following baseline.

- Outcome measures were based on self-report screening tools to assess levels of anxiety and depressive symptomatology.

\section{INTRODUCTION}

Mental illness presents a substantial burden for public health in Canada, with approximately one in five Canadians ${ }^{1}$ experiencing mental illness during their lifetime. Mental illness places considerable strain on the Canadian economy, with an estimated cost of US $\$ 49$ billion per year in direct healthcare costs, out-of-pocket expenses, lost productivity, declines in overall quality of life, and premature mortality. ${ }^{12}$ Those with mental illness are at higher risk of developing comorbidities, ${ }^{12}$ and experience lower life expectancy compared with the general population. ${ }^{1}$ Women consistently experience higher burdens of mental illness compared with men, ${ }^{34}$ with estimates of Canadian anxiety and depression demonstrating higher prevalence of these disorders among women $(3.2 \%$ and $5.8 \%)$ vs men $(2.0 \%$ and $3.6 \%) .{ }^{3}$ Women also experience these conditions as comorbidities more commonly than men. ${ }^{15}$ Estimates from samples of mothers suggest especially high prevalence of anxiety $(15.0 \%-18.2 \%)$ and depression (18.5\%-22.0\%) among pregnant mothers, ${ }^{5}$ and depression $(10 \%-42 \%)$ among mothers of young children. ${ }^{6} 7$ This 
high burden is worrisome, as maternal mental illness is both detrimental to maternal health, and has been linked to emotional and behavioural issues among their young children. ${ }^{568}$

In addition to individual risk factors for mental illness, such as income and education, ${ }^{9}{ }^{10}$ the social determinants of health including the characteristics of the environment where individuals live could play an important role. $^{10}{ }^{11}$ One such social determinant is income inequality, or the unequal distribution of incomes in a given area. ${ }^{10-12}$ As income inequality increases, invidious social comparisons could emerge between individuals and groups. ${ }^{11} 12$ These social comparisons could lead to feelings of shame, isolation, and ultimately poor mental health. ${ }^{411}$ Income inequality might also erode social cohesion, which has been identified as a protective factor for adverse mental health, ${ }^{13}$ resulting in a breakdown in trust between members of a neighbourhood or community. ${ }^{11}{ }^{12}$ Although evidence has suggested a lag-period between exposure to income inequality and the onset of poor health via these mechanisms, ${ }^{14}$ a time frame for mental health outcomes among women and mothers has not been specified. Thus, longitudinal data for these populations are needed.

Mothers are likely especially susceptible to the mechanisms of stressful social comparisons and eroding social cohesion due to gendered life experiences and social networks. Research indicates that women tend to place more value on the collective (ie, others) than the self, compared with men, ${ }^{16}$ and thus may be especially susceptible to social comparisons with others as they transition to parenthood and worry about being perceived as a 'perfect parent'. ${ }^{517}$ Women's social networks are also typically comprised of more local connections (eg, family, friends, neighbours) compared with men, ${ }^{18}{ }^{19}$ suggesting that the erosion of support at the scale of neighbourhoods could be especially detrimental. For example, a study of inner-city mothers in London reported that those who had adequate social support at baseline and then lost that support over time had an elevated risk of experiencing depression. ${ }^{19}{ }^{20}$ It is possible, then, that the erosion of social cohesion engendered by income inequality over time could present barriers for pregnant and new mothers in accessing their social networks and supports, resulting in heightened stress, isolation, and adverse mental health.

A recent review ${ }^{4}$ found that the majority of studies linking income inequality and depression reported significant associations between higher inequality and risk of depression, with a pooled risk ratio of $1.19(95 \% \mathrm{CI}=1.07$ to $1.31)$. Various studies at the neighbourhood and community levels have also found significant associations between inequality and psychological and emotional distress, ${ }^{21}{ }^{22}$ self-esteem and anger, ${ }^{23}$ depression and depressive symptoms, ${ }^{24}{ }^{25}$ and anxiety symptoms. ${ }^{26}{ }^{27}$ However, some studies at the neighbourhood level reported no significant link between inequality and mental disorders. ${ }^{28-30}$ The implications of current findings are limited, as many of these studies are cross-sectional. ${ }^{21-29}$ More longitudinal studies at the neighbourhood level are needed to further clarify these associations.

Research linking income inequality to maternal mental health, while sparse, has also yielded some insights. To our knowledge, only one study has focused specifically on mothers. ${ }^{31}$ This study of American mothers with children aged 26-48 months found that those living in moderately unequal states (Gini $=0.416-0.430$ ) had $40 \%$ higher odds of experiencing depression compared with those living in low inequality states $(\mathrm{Gini} \leq 0.415)$, with stronger impacts felt among low income mothers. ${ }^{31}$ As this study is cross-sectional and based on data from several decades ago, more contemporary research with this population is needed. Additionally, no studies have included pregnant women as a distinct population, despite the unique physiological and social changes that they experience as they transition to parenthood. ${ }^{5}$

The current study addresses gaps in the literature by conducting a longitudinal study using retrospective cohort data of neighbourhood-level income inequality and mental health outcomes specifically among pregnant and new mothers. This multilevel approach allowed us to account for various individual and area-level risk factors of poor mental health that are potentially linked to changes in income inequality, ${ }^{4} 1032$ and consider the temporal and potentially lagged impacts of inequality on maternal mental health. Based on previous findings, ${ }^{4-27} 31$ we hypothesised that greater inequality would be associated with more severe anxiety and depressive symptomatology, and that these impacts would be more severe among those with less absolute household income.

\section{METHODS}

\section{Patient and public involvement}

Study participants or the public were not involved in the design, analysis, and interpretation of this study.

\section{Sample}

Maternal data are from the All Our Families (AOF) study, an ongoing community-based cohort of mothers living in Calgary, the largest city in the province of Alberta, Canada. ${ }^{33}$ Participants have similar demographic characteristics compared with other parenting women in Calgary, but are more likely to be married and have higher household income. Longitudinal data from women 18 years and older were collected via questionnaires administered between 2008 and 2014 at six time points: $<25$ weeks and 34-36 weeks pregnant, and 4 months and 1, 2 and 3 years post partum. The AOF investigators defined women as continuing participants if they completed at least one follow-up survey during the 1, 2 and 3-year postpartum follow-up points. Thus, not all AOF participants sampled at baseline have outcome data at each subsequent collection point. Of the initial 3387 participants, those who were retained during follow-up tended to be older, richer, more highly educated, in a relationship, 
speak primarily English at home, and native to Canada, compared with those who actively withdrew $(n=235)$ or were lost to follow-up $(\mathrm{n}=669) .{ }^{34}$

In total, 2461 AOF mothers could be linked to 196 Calgary neighbourhoods via postal code information provided at baseline, and were not missing baseline data on mental health outcomes and key individual-level covariates. These mothers formed our main analytical sample. To account for prior experience of anxiety, a subsample was generated excluding mothers from our main sample who had elevated anxiety symptoms at baseline (untransformed Spielberger State Anxiety Inventory (SSAI) cut-off score of $\geq 40^{35}$ ) to account for prior experience of anxiety. This process yielded a subsample of 2047 mothers nested within 192 neighbourhood. Similarly, another subset was generated excluding mothers from our main sample who had elevated depressive symptoms at baseline (untransformed Edinburgh Postnatal Depression Scale (EPDS) cut-off score $\geq 10^{36}$ ) to adjust for prior experience of depression. This subset consisted of 2047 mothers nested within 191 neighbourhoods.

Neighbourhoods for this study were characterised using 2006 Canadian Census data at the dissemination area (DA) level for the City of Calgary. DAs represent the smallest standard geographic units at which all Canadian census data are disseminated. ${ }^{37}$ These areas, which cover the entire territory of Canada and respect the boundaries of census tracts and subdivisions, typically encompass populations of 400-700 individuals. ${ }^{37}$ Each DA was spatially linked to the corresponding Calgary community neighbourhoods, with many neighbourhoods encompassing multiple DAs. According to 2011 Calgary Civic Census data, residential Calgary community neighbourhoods range in population size from 1 to 19851 residential dwellings. ${ }^{38}$

\section{Measures}

Area-level covariates

Neighbourhood-level income inequality was measured using Gini coefficients; a commonly used measure of income inequality ranging from 0.0 (perfect equality) to 1.0 (perfect inequality). Methods for calculating Gini coefficients have been described elsewhere. ${ }^{39}$ Values were calculated for the Calgary neighbourhoods using 2006 after-tax income census data ${ }^{40}$ and standardised using z-transformation.

Economic neighbourhood characteristics included the proportion of households earning an annual income greater than US $\$ 100000$ as an indicator of neighbourhood socioeconomic status, as well as the proportion of households living below the after-tax low-income cut-off that serves as an indication of higher concentration of poverty. ${ }^{41}$ Demographic neighbourhood characteristics included were the proportion of individuals who identified as recent immigrants (immigrated to Canada between 2001 and 2006) and those who identified as belonging to a visible minority (ie, non-Caucasian, not including indigenous or aboriginal peoples). These area-level measures were linked to AOF mothers using postal codes collected at baseline and were dichotomised using median scores as cut-offs.

\section{Individual-level covariates}

Baseline sociodemographic covariates included from the AOF dataset were household income, age, ethnicity, highest level of education completed, and marital status. Participants were categorised into higher ( $\geq$ US\$80000 per year) and lower (US\$79999 or less per year) incomes using AOF income categories. Baseline age was meancentred and included as a continuous measure, and the remaining covariates were dichotomised. Follow-up time was characterised as the time in months from the first questionnaire to each subsequent data collection point.

\section{Outcomes measures}

From $<25$ weeks pregnant to 1-year post partum, depressive symptoms were measured using the EPDS. ${ }^{36} 42$ This scale was designed to screen for depression in pregnant and early postpartum women ${ }^{736}$ and based on 10 items that assess depressive symptoms experienced over the past 7 days. The EDPS has demonstrated a sensitivity and specificity of 0.91 and 0.76 , respectively, when screening for depression at 6-8 weeks following delivery. ${ }^{42}$ At 2 and 3 years post partum, AOF investigators changed from the EPDS to the Centre for Epidemiological StudiesDepression (CES-D) scale. This scale was developed to assess depressive symptomatology in the general population, based on 20 items of symptoms experienced in the past week. ${ }^{743}$ The CES-D demonstrated a sensitivity of 1.00 and a specificity of 0.65 among a sample of low income African American pregnant women and mothers when screening for major and minor depression. ${ }^{7}$

Continuous EPDS and CES-D depressive symptom scores were standardised using the percent of maximum possible (POMP) scaling method to create one continuous measure of depressive symptomatology over the entire study period. ${ }^{44}$ Both scales measure similar key constructs of depression experienced in the past 7 days (depressed affect and positive affect), ${ }^{43}$ and both have been used in studies with pregnant and postpartum mothers. ${ }^{7314345}$ When comparing their performance, both scales demonstrated indistinguishable accuracy (group $\chi^{2}=0.50, \mathrm{p}=0.78$ ) when screening for prenatal and postpartum depressive symptoms among a sample of African American mothers. ${ }^{7}$

Continuous anxiety symptom scores were measured using the SSAI, described previously. ${ }^{35}$ Scores are calculated using 20 items of how respondents feel 'at this moment'. The SSAI has demonstrated sufficient construct validity with other anxiety scales, and sufficient test-retest reliability (test-retest coefficient of up to 0.86). ${ }^{35} \mathrm{As}$ with depressive symptom scores, SSAI scores were standardised using the POMP scaling method. ${ }^{44}$ Both continuous anxiety and depression outcome scores were $\log$ transformed to adjust for positively skewed distributions. 


\section{Statistical analyses}

Growth curve multilevel modelling with mixed-effect multiple linear regression was used to quantify the longitudinal relationships between neighbourhood income inequality and maternal anxiety and depressive symptoms. First, intercept-only models were constructed to calculate intraclass correlation coefficients (ICCs). ICCs indicate how much variability of anxiety and depressive symptoms can be attributed to neighbourhood and individual levels. Subsequently, neighbourhood income inequality and time (model 1), individual-level covariates (model 2) and neighbourhood-level characteristics (model 3) were added into the models. Cross-level interaction terms between income inequality, household income, and time (model 4) were added to determine if associations between income inequality and mental health differed across levels of household income. Quadratic and cubic parameters for time were tested to account for potential non-linear trajectories of anxiety and depressive symptoms over time. These parameters not statistically significant, however, and so only linear parameters for time were retained.

As prior experience of mental illness is often a strong risk factor for of recurrent mental illness, ${ }^{16}$ analyses of continuous anxiety symptoms over time were conducted using the sample of AOF mothers who did not have elevated anxiety symptoms at baseline $(n=2047)$ to adjust for experience of anxiety prior to follow-up. Similarly, analyses of continuous depressive symptoms were conducted using the sample of mothers without elevated depressive symptoms at baseline $(\mathrm{n}=2047)$ to adjust for experience of depression prior to follow-up. Analyses of anxiety and depressive symptoms were repeated using the full sample of mothers $(n=2461)$, although these results did not differ from the above sets of analyses and thus are not presented.

Multilevel growth curve modelling allowed us to account for the clustering of repeated measured within mothers nested within neighbourhoods, and the intercepts of maternal and neighbourhood covariates were allowed to vary. Furthermore, this analytical approach allowed us to adjust for multiple known confounders, and accommodate unequally spaced time points and missing outcome values over the course of follow-up. ${ }^{46}$ All statistical tests were two sided $(\mathrm{p} \leq 0.05)$ and run using Stata (V.15.1) accessed via a secured virtual environment. ${ }^{47}$

\section{RESULTS}

Baseline characteristics of the two samples of AOF mothers are presented in table 1. A large proportion of mothers from both samples were married or common-law $(95.5 \%$ and $95.6 \%)$, white $(80.1 \%$ and $80.6 \%)$, higher income $(73.1 \%$ and $73.5 \%)$, and had at least some postsecondary education $(91.2 \%$ and $91.6 \%)$. The mean age was of the mothers in both samples was 30.8 years $(\mathrm{SD}=4.4)$. Neighbourhood characteristics of the Calgary neighbourhoods captured in both samples are also presented in table 1 .
The mean neighbourhood Gini value for both samples was $0.35(\mathrm{SD}=0.06$; range $=0.20,0.60)$, which is higher than 2006 after-tax Gini estimates for both Alberta (0.31) and Canada (0.32). ${ }^{48}$ The two samples did not differ significantly in terms of individual and area-level characteristics.

Anxiety and depressive symptom scores, as well as the proportions of mothers with elevated symptoms, are presented in table 2 for each data collection point. Tracking mothers from $<25$ weeks of pregnancy to 3 years post partum, mean anxiety and depressive symptom scores ranged from 13.4 to 17.5 and 11.2 to 13.9 , respectively, with both peaking at 34-36 weeks of pregnancy. Over the course of follow-up, the prevalence of mental health burden ranged from $10.0 \%$ to $13.1 \%$ for elevated anxiety and $7.9 \%$ to $9.1 \%$ for elevated depression. The cumulative incidence of first occurrence of elevated symptoms over the follow-up period was 267 cases/1000 mothers for elevated anxiety and 210 cases $/ 1000$ mothers for elevated depression.

According to the intercept-only models for mothers without elevated anxiety symptoms at baseline $(n=2047)$, the ICC for anxiety symptoms was $0.0042(95 \% \mathrm{CI}=0.00042$ to 0.040 ), meaning that $0.42 \%$ of the variance in anxiety symptoms was explained by area-level characteristics. For model 1, while neighbourhood Gini was not significantly associated with anxiety symptoms at baseline, there was a significant interaction between Gini and time in months $(\beta=0.0017,95 \% \mathrm{CI}=0.00049$ to $0.0028 ; \mathrm{p}=0.005)$ indicating an excess rate of change in average anxiety symptom scores over time by level of inequality (table 3; figure 1A). In this model, a standardised deviation increase in income inequality was associated with an excess average monthly rate increase of $0.0017 \log$ anxiety units (corresponding to a $1.001 \%$ increase in average anxiety scores) per month. This association remained consistent after adjusting for individual and neighbourhood-level covariates (models 2 and 3), and was slightly attenuated but remained significant when testing inequality and household income interactions (model 4). There was no evidence of interaction between inequality and household income on changes in anxiety symptoms.

Among mothers without elevated depressive symptoms at baseline $(\mathrm{n}=2047), 0.27 \%$ of the variation is depressive symptoms was explained by neighbourhood-level characteristics (ICC $=0.0027$; $95 \% \mathrm{CI}=0.00019$ to 0.037 ). For all models, we found no statistical evidence for a significant association between income inequality and changing depressive symptoms at baseline or over time, despite depressive symptoms demonstrating similar effect sizes and average score trajectories to anxiety symptoms (table 3; figure 1B). There was also no evidence of crosslevel inequality and household income interactions for depressive symptoms.

\section{DISCUSSION}

To our knowledge, this current study is the first to investigate the relationships between income inequality 
Table 1 Baseline sociodemographic and neighbourhood characteristics of included 'All Our Families' cohort mothers without baseline elevated anxiety symptoms $(n=2047)$ or elevated depressive symptoms $(n=2047)$

\begin{tabular}{|c|c|c|c|}
\hline Maternal characteristics & $\begin{array}{l}\text { Mothers without } \\
\text { baseline anxiety }(n=2047)\end{array}$ & $\begin{array}{l}\text { Mothers without } \\
\text { baseline depression ( } n=2047)\end{array}$ & $P$ value \\
\hline \multicolumn{4}{|l|}{ Maternal ethnicity (\%) } \\
\hline White & $1639(80.1 \%)$ & $1650(80.6 \%)$ & 0.665 \\
\hline Non-white & $408(19.9 \%)$ & $397(19.4 \%)$ & \\
\hline \multicolumn{4}{|l|}{ Household Income (\%) } \\
\hline US $\$ 80000$ or more & $1497(73.1 \%)$ & $1505(73.5 \%)$ & 0.777 \\
\hline US $\$ 79999$ or less & $550(26.9 \%)$ & $542(26.5 \%)$ & \\
\hline \multicolumn{4}{|l|}{ Maternal education (\%) } \\
\hline At least some post-secondary & $1867(91.2 \%)$ & $1866(91.6 \%)$ & 0.956 \\
\hline High school or less & $180(8.8 \%)$ & $181(8.8 \%)$ & \\
\hline \multicolumn{4}{|l|}{ Marital status (\%) } \\
\hline Married/common-law & $1954(95.5 \%)$ & $1956(95.6 \%)$ & 0.880 \\
\hline Single/divorced/widowed & $93(4.5 \%)$ & $91(4.6 \%)$ & \\
\hline Maternal age (mean years/SD) & 30.8 (4.4) range: $18-47$ & $30.8(4.4)$ range: $18-47$ & 1.000 \\
\hline Neighbourhood characteristics & Mean (SD) $(n=192)$ & Mean (SD) $(n=191)$ & $P$ value \\
\hline Gini coefficient & $0.35(0.06)$ range: $0.20-0.60$ & $0.35(0.06)$ range: $0.20-0.60$ & 0.9154 \\
\hline $\begin{array}{l}\text { Neighbourhood Income } \\
\text { Household above } 100 \mathrm{k}(\%)\end{array}$ & $30.0 \%$ (15.8\%) range: $3.3-75.7 \%$ & $30.0 \%(15.8 \%)$ range: $3.3-75.7 \%$ & 0.9714 \\
\hline LICO (\%) & $5.0 \%(5.5 \%)$ range : $0.0-53.3 \%$ & $5.0 \%(5.5 \%)$ range: $0.0-53.3 \%$ & 0.9346 \\
\hline \multicolumn{4}{|l|}{ Neighbourhood composition } \\
\hline Visible minority (\%) & $21.7 \%(16.7 \%)$ range: $0.0-81.9 \%$ & $21.5 \%(16.1 \%) 0.0-79.5 \%$ & 0.8816 \\
\hline Recent immigrant (\%) & $5.5 \%$ (4.3\%) range: $0.0-26.8 \%$ & $5.5 \%(4.3 \%)$ range: $0.0-26.8 \%$ & 0.9711 \\
\hline
\end{tabular}

LICO, low-income cut-off.

and mental health following mothers from pregnancy to several years post partum. This research builds on previous work demonstrating that increasing inequality is linked to poorer mental health among mothers of young children. ${ }^{31}$ Our results indicate that income inequality is associated with different rates of change of maternal mental health symptoms over time, with high levels of inequality relating to upward trends in average anxiety symptom scores (figure 1A). Our findings align with previous studies linking inequality to adverse mental health outcomes. ${ }^{21} 22$ 24-28 In particular, two studies of adolescents in Iceland demonstrated associations between increasing community-level inequality and higher anxiety symptoms. ${ }^{26} 27$ These studies also did not find significant associations between inequality and changing depressive symptoms. Additionally, while we did not find evidence of an interaction effect between inequality and household income on mental health, our results still provide support for the income inequality hypothesis. ${ }^{11} 2127$ If income inequality elicits poor mental health via social comparisons and eroding social cohesion, its impacts (eg, mistrust, social isolation, loss of social capital) would likely be felt by all members of a community, not just the poorest or most disadvantaged. ${ }^{11} 12$
Our results conflict with previous work reporting associations between income inequality and depression outcomes. ${ }^{42431}$ A potential explanation is that heightened anxiety could be a more immediate response to high income inequality, while worsening depression could emerge through the more gradual erosion of social cohesion. ${ }^{11} 1227$ The discrepancy could also be due to contextual differences, as much of the literature linking inequality and mental health is based in the USA. ${ }^{4}$ Depression could be impacted by inequality more heavily in the USA, as the United States has notably high levels of inequality and poorer social safety nets. ${ }^{10}$ However, when comparing the estimated trajectories of average mental health symptom scores (figure 1) and model coefficients (table 3), we observed similar trajectories for depressive and anxiety symptoms by level of neighbourhood income inequality despite a lack of statistical significance for depressive symptoms. From a practical standpoint, these trends suggest that higher levels of neighbourhood income inequality could be prompting the divergence of various mental health symptom trajectories over time. Targeted mental health screening of mothers living in especially unequal areas is one approach that could help identify and address this divergence. 
Table 2 Maternal mental health outcomes at baseline and follow-up (times Q1-Q6) for pregnant women and mothers from the All Our Families cohort (2008-2014)

$\begin{array}{llllll}\text { Q1* } & \text { Q2 } & \text { Q3 } & \text { Q4 } & \text { Q5 } & \text { Q6 }\end{array}$

Mothers without baseline anxiety

Anxiety scores†

\begin{tabular}{|c|c|c|c|c|c|c|}
\hline $\begin{array}{l}\text { Anxiety symptoms } \\
\text { (mean/SD) }\end{array}$ & $13.4(8.8)$ & $17.5(12.7)$ & $14.7(13.2)$ & $16.3(13.7)$ & $15.8(12.6)$ & $15.6(13.3)$ \\
\hline $\begin{array}{l}\text { Elevated anxiety } \\
\text { symptoms (\%) }\end{array}$ & $0 \%(n=0)$ & $13.1 \%(n=252)$ & $10.0 \%(n=185)$ & $12.8 \%(n=121)$ & $11.0 \%(n=111)$ & $10.4 \%(n=132)$ \\
\hline Total observation (n) & 2047 & 1928 & 1850 & 945 & 1010 & 1269 \\
\hline \multicolumn{7}{|c|}{ Mothers without baseline depression } \\
\hline \multicolumn{7}{|l|}{ Depression scoresł } \\
\hline $\begin{array}{l}\text { Elevated depression } \\
\text { symptoms (\%) }\end{array}$ & $0 \%(n=0)$ & $8.6 \%(n=168)$ & $7.9 \%(n=150)$ & $8.1 \%(n=79)$ & $9.1 \%(n=92)$ & $8.9 \%(n=114)$ \\
\hline Total observation (n) & 2047 & 1963 & 1902 & 981 & 1007 & 1278 \\
\hline
\end{tabular}

*Times points correspond to <25 weeks pregnant (Q1), 34-36 weeks pregnant (Q2), 4 months postpartum (Q3), 1 year (Q4), 2 years (Q5) and 3 years (Q6) post partum.

†Anxiety symptoms were measured using the Spielberger State Anxiety Inventory at time points Q1-Q6 (score $\geq 40=$ elevated anxiety symptoms). Continuous scores are presented on POMP scale.

‡Depressive symptoms were measured using the Edinburgh Postnatal Depression Scale at time points Q1-Q4 (score $\geq 10=e l e v a t e d$ depressive symptoms) and the Centre for Epidemiologic Studies Depression Scale at time points Q5-Q6 (score $\geq 16=$ elevated depressive symptoms). Continuous scores are presented on POMP scale.

POMP, percent of maximum possible.

Notably, the low level of variance in outcomes at the neighbourhood level suggests that area-level characteristics such as income inequality can only account for a small portion of individual health outcomes. ${ }^{27}$ Further, the effect sizes of our statistically significant findings are relatively small in magnitude. However, even lower levels of mental health symptoms (eg, subclinical symptom levels) are of public health concern, as they have been identified as predictors of the onset of mental illness over time. ${ }^{49}$ In terms of exposures, as opposed to individuallevel factors such as income or marital status, income inequality is a feature of the shared socioeconomic environment meaning that everyone living within an unequal area is exposed to that inequality. Income inequality has also been linked to a variety of other health conditions, including heart disease, poorer self-rated health and shorter life expectancy. ${ }^{11} 12$ Thus, while inequality might only explain a modest amount of variation for a given individual health outcome, it could impact a large range of health outcomes. As such, working to shift the distribution of exposure in a 'healthier' direction (ie, towards greater income equality) could present considerable population health benefits. ${ }^{50}$ When combining our findings with existing literature, there is sufficient indication that mitigating the impacts of inequality could have various benefits for social equity and population health.

A main strength of this study was its longitudinal multilevel approach capturing a 6 year data collection period. Multilevel modelling allowed us to analyse trends over time while accounting for unequally spaced time points and incomplete outcome data. ${ }^{46}$ This longitudinal approach enabled us to capture the divergence of longitudinal mental health symptom trends over time, establish temporality between exposure and changing mental health outcomes, and capture lag effects between exposure to inequality and changing anxiety symptoms. We considered anxiety and depressive symptomatology as distinct mental health outcomes, rather than focusing solely on depression or general mental illness. This distinction prevents the conflation of different forms of adverse psychological outcomes, and enabled us to consider the pathways between inequality and specific mental health outcomes. Finally, by conducting our study at the level of city neighbourhoods, we were presented with a broad range of income inequality between neighbourhoods. Choosing this geographical scale allowed us to avoid the constraints of previous Canadian work at the province level, which highlighted the small range of income inequality between Canadian provinces as a potential explanation for non-significant findings. ${ }^{51}$

Our findings should be interpreted within the context of study limitations. Data on residence following baseline were not available, so some mothers might have moved during the study period, thus affecting their exposure and introducing exposure misclassification. This limitation also restricted income inequality estimates to 2006, and prevented us from capturing income inequality during the study period (eg, changes resulting from the 2008 economic recession). Of note, the large decrease in participants after Q3 was primarily due to timing and 
Table 3 Associations between individual and neighbourhood characteristics with anxiety and depressive symptoms among mothers without elevated anxiety $(n=2047)$ or depressive $(n=2047)$ symptoms at baseline from the All Our Families cohort $(2008-2014)^{\star}$

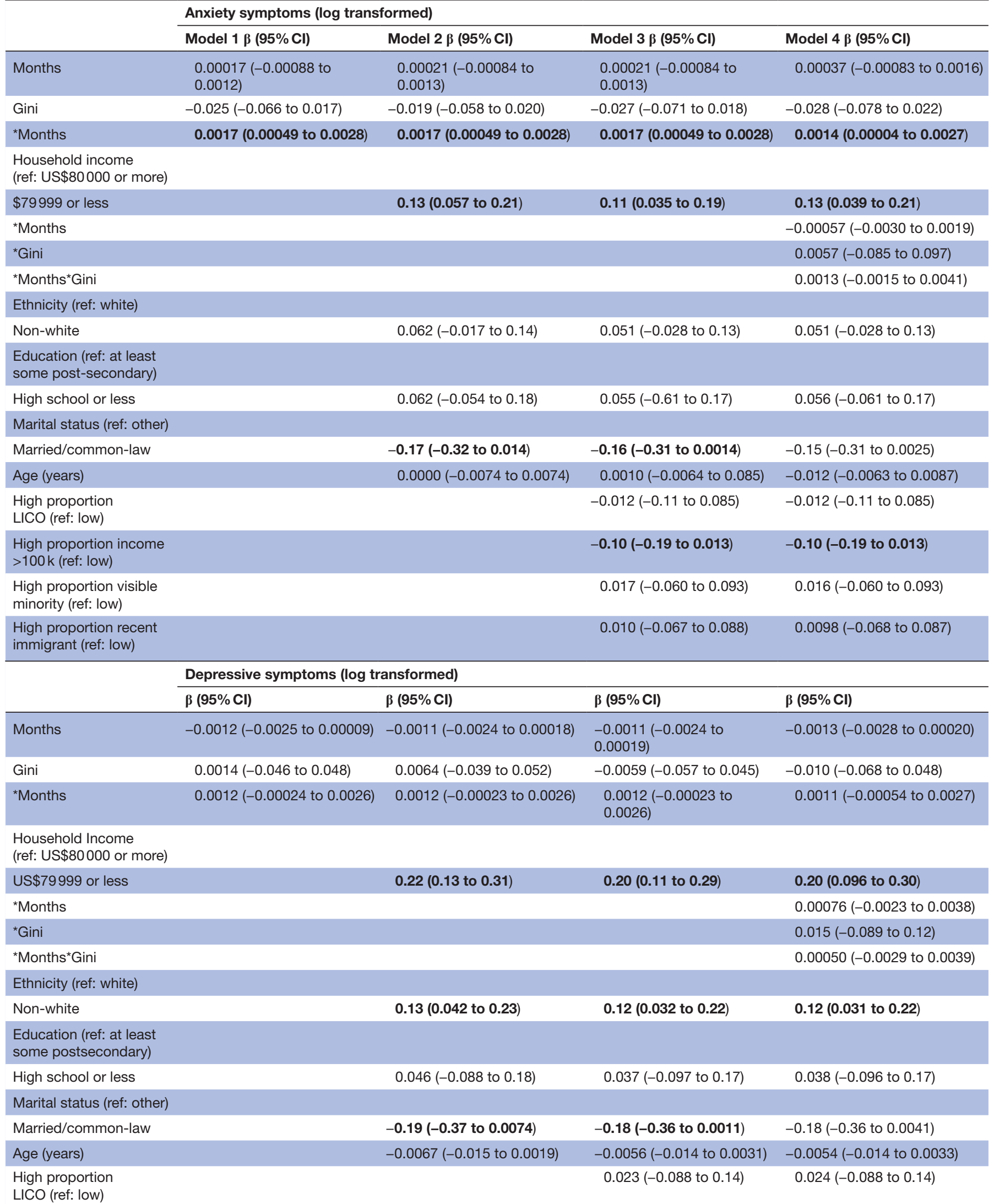


Table 3 Continued

\begin{tabular}{|c|c|c|c|c|}
\hline & \multicolumn{4}{|c|}{ Depressive symptoms (log transformed) } \\
\hline & $\beta(95 \% \mathrm{Cl})$ & $\beta(95 \% \mathrm{Cl})$ & $\beta(95 \% \mathrm{Cl})$ & $\beta(95 \% \mathrm{Cl})$ \\
\hline $\begin{array}{l}\text { High proportion income } \\
>100 \mathrm{k} \text { (ref: low) }\end{array}$ & & & $-0.068(-0.17$ to 0.035$)$ & $-0.069(-0.17$ to 0.034$)$ \\
\hline $\begin{array}{l}\text { High proportion visible } \\
\text { minority (ref: low) }\end{array}$ & & & $0.040(-0.048$ to 0.13$)$ & $0.040(-0.048$ to 0.13$)$ \\
\hline $\begin{array}{l}\text { High proportion recent } \\
\text { immigrant (ref: low) }\end{array}$ & & & $-0.012(-0.10$ to 0.078$)$ & $-0.012(-0.10$ to 0.077$)$ \\
\hline
\end{tabular}

${ }^{*}$ Bolded values indicate statistical significance at $\mathrm{p} \leq 0.05$. LICO, low-income cut-off.

logistical issues, rather than purely due to lost to follow-up or withdraw. However, 938 mothers from the initial AOF cohort withdrew or were lost to follow-up between Q1 and Q6, with mothers who remained in the study tending to be richer, born in Canada, in a relationship, and have higher educational attainment. ${ }^{34}$ These differences could have introduced selection bias into the study, and limits the generalisability of our findings to broader populations. In a similar vein, our small effect sizes and limited generalisability could be due in part to the large proportion of white, rich, highly educated and married participants in our study sample. As income inequality has been shown to be especially detrimental to the mental health for those of lower socioeconomic status, ${ }^{25} 2631$ we might have observed greater effect size estimates had we captured a more socioeconomically heterogeneous sample.

The use of self-report outcome measures could have introduced misclassification, and using two different tools (EPDS and CES-D) to construct a continuous longitudinal measure of depressive symptoms could have generated measurement bias, despite the POMP scaling approach. However, both depression scales focus on constructs surrounding depressed and positive affect, ${ }^{43} 45$ have been validated and widely-used in both perinatal and
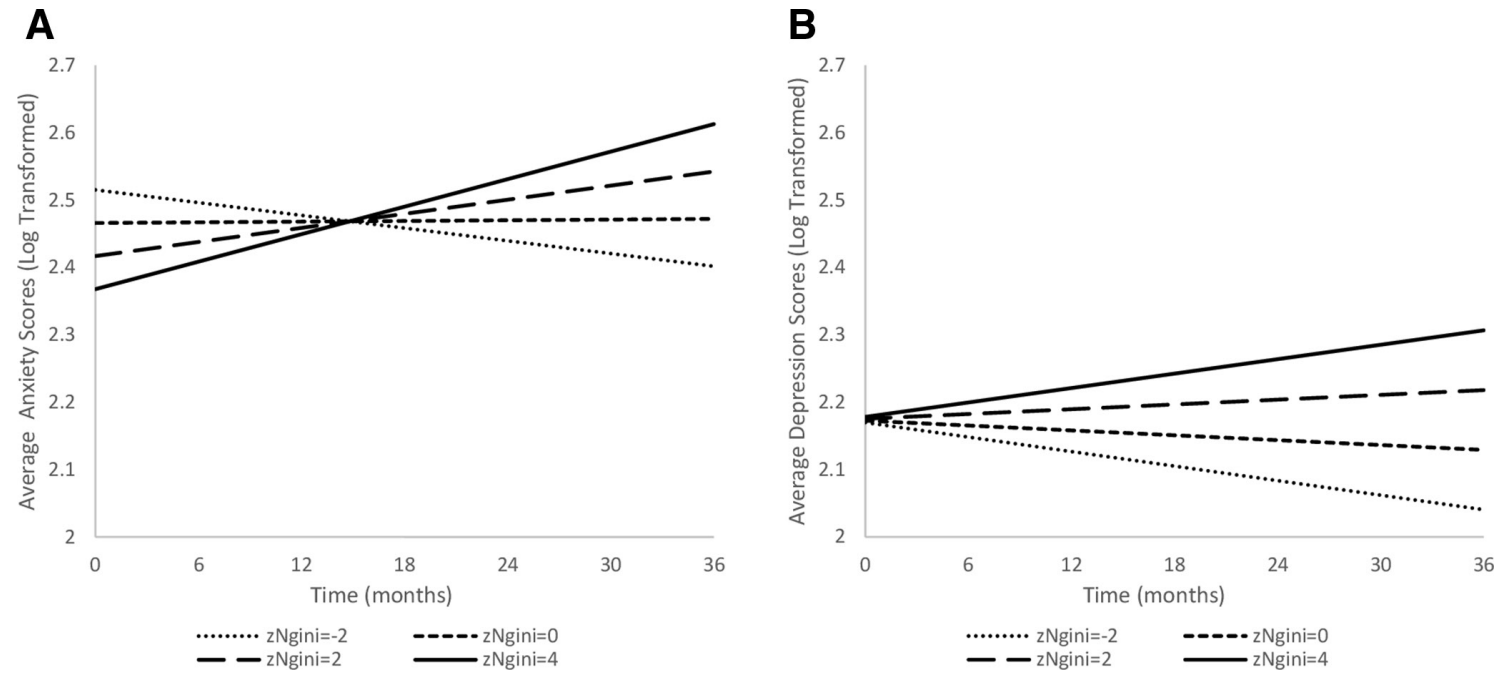

Figure 1 Estimated trajectories of log-transformed anxiety symptoms (A) and depressive symptoms (B) of AOF mothers without elevated baseline anxiety $(n=2047)$ or depressive $(n=2047)$ symptoms over time by level of neighbourhood income inequality. AOF, All Our Families.

general population settings, ${ }^{7314345}$ and demonstrated the same accuracy when screening the same sample of pregnant and postpartum mothers. ${ }^{7}$ Due to the observational nature of our study, we were unable to account for all potential confounders such as subjective social status ${ }^{25} 29$ and stressful past life events (eg, difficulties with childbirth, pregnancy intent), ${ }^{52}$ and thus our results might not fully account for key factors influencing changes in maternal mental health and be influenced by residual confounding.

The current study addresses gaps in the literature by exploring the longitudinal associations between income inequality and mental health among pregnant and new mothers living in Calgary. Our findings provide a foundation for future studies to continue investigating the relationship between income inequality and mental health among mothers during pregnancy and into the early postpartum period. Considering the unique physiological and social experiences of pregnant and new mothers, similar studies that consider all residents of our included neighbourhoods would be useful to determine if associations between inequality and mental health also exist for more general urban populations. Similar studies would also benefit from including exposure data that encompass 
periods of economic strain, such as the 2008 economic recession that has been linked to changes in income inequality ${ }^{53}$ and heightened prevalence of mental illness in Canada and worldwide ${ }^{5455}$ As the specific mechanisms linking inequality to health remain unclear, research on the mediating role of stressful comparisons, relative deprivation, and social cohesion could help clarify these associations. Finally, we recommend future studies on the mental health impacts of interventions that aim to address the broader socioeconomic contexts of income inequality, such as minimum wage increases. By considering the impacts of inequality and promoting equitable intervention, we can address mental health in a more comprehensive way for mothers, their children, and the general population.

Twitter Samuel AJ Lowe @Sammomeow1, Sheila McDonald @sheilawmcdonald, Candace IJ Nykiforuk @nykiforuk_c and Roman Pabayo @RPabayo

Acknowledgements The authors acknowledge Darcy Reynard for linking the AOF mothers to the Canadian census data and generating Gini coefficients and other neighbourhood variables for the study neighbourhoods. The authors also acknowledge the contribution and support of AOF participants and AOF team members. Suzanne Tough is the Principal Investigator of the AOF. Finally, the authors acknowledge SAGE (Secondary Analysis to Generate Evidence), the secure data repository developed by PolicyWise for Children and Families for providing access to these data.

Contributors SAJL made substantial contributions for the conception and design of this project, the acquisition, analysis, interpretation of data, the acquisition of funding and drafting the manuscript, and is responsible for the overall content as the guarantor. SM made substantial contributions to the conception of this project and the implementation and management of the AOF cohort study. AS made substantial contributions to the design of this project, the analytical plan of the project, and the supervision of SAJL. CN made substantial contributions to the design of this project and the supervision of SAJL. RC made substantial contributions to the conception of this project. RP made substantial contribution to the conception and design of this project, the acquisition, analysis and interpretation of data, and acquisition of funding. All authors were involved in the drafting or critical revising of the manuscript and have approved the final version of the manuscript.

Funding This research has been funded by the generosity of the Stollery Children's Hospital Foundation and supporters of the Lois Hole Hospital for Women through the Women and Children's Health Research Institute, as well as the MSI Foundationgrant number 896. Dr. Roman Pabayo is a Tier II Canada Research Chair in social and health inequities throughout the lifespan.

\section{Competing interests None declared.}

Patient and public involvement Patients and/or the public were not involved in the design, or conduct, or reporting, or dissemination plans of this research.

Patient consent for publication Not applicable.

Ethics approval Ethical approval for this study was provided by the Research Ethics Office, University of Alberta (study ID: Pro00083081; project ID: RES0040064RA).

Provenance and peer review Not commissioned; externally peer reviewed.

Data availability statement Data may be obtained from a third party and are not publicly available. Data from the AOF cohort are available through a data access request directly through the All Our Families Study (https://allourfamiliesstudy.com/ data-access/) or through Secondary Analysis to Generate Evidence (PolicyWise for Children and Families; https://redcap.ualberta.ca/surveys/?s=HALHFCRTHL)

Open access This is an open access article distributed in accordance with the Creative Commons Attribution Non Commercial (CC BY-NC 4.0) license, which permits others to distribute, remix, adapt, build upon this work noncommercially, and license their derivative works on different terms, provided the original work is properly cited, appropriate credit is given, any changes made indicated, and the use is non-commercial. See: http://creativecommons.org/ licenses/by-nc/4.0/.

\section{ORCID iDs}

Samuel AJ Lowe http://orcid.org/0000-0003-0196-3768

Sheila McDonald http://orcid.org/0000-0002-5950-7098

Ambikaipakan Senthilselvan http://orcid.org/0000-0002-6631-1376

Candace IJ Nykiforuk http://orcid.org/0000-0002-1017-5475

Roman Pabayo http://orcid.org/0000-0003-4018-4898

\section{REFERENCES}

1 Smetanin P, Stiff D, Briante C. Life and economic impact if major mental illnesses in Canada the impact of mental illness in Canada: 2011 to 2041 . RiskAnalytica, on behalf of the mental health Commission of Canada, 2011. Available: https://www.mentalhealth commission.ca/sites/default/files/MHCC_Report_Base_Case_FINAL_ ENG 0 0.pdf [Accessed 11 Jan 2021].

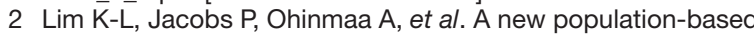
measure of the economic burden of mental illness in Canada. Chronic Dis Can 2008;28:92-8.

3 Pearson C, Janz T, Ali J. Health at a glance - mental and substance use disorders in Canada. Statistics Canada, catalogue no. 82-624-X, 2013. Available: https://www150.statcan.gc.ca/n1/pub/82-624-x/ 2013001/article/11855-eng.htm [Accessed 11 Jan 2021].

4 Patel V, Burns JK, Dhingra M, et al. Income inequality and depression: a systematic review and meta-analysis of the association and a scoping review of mechanisms. World Psychiatry 2018:17:76-89.

5 Teixeira C, Figueiredo B, Conde A, et al. Anxiety and depression during pregnancy in women and men. $J$ Affect Disord 2009;119:142-8.

6 Horwitz SM, Briggs-Gowan MJ, Storfer-Isser A, et al. Persistence of maternal depressive symptoms throughout the early years of childhood. J Womens Health 2009;18:637-45.

7 Tandon SD, Cluxton-Keller F, Leis J, et al. A comparison of three screening tools to identify perinatal depression among low-income African American women. J Affect Disord 2012;136:155-62.

8 McDonald $\mathrm{S}$, Kehler $\mathrm{H}$, Bayrampour $\mathrm{H}$, et al. Risk and protective factors in early child development: results from the all our babies (AOB) pregnancy cohort. Res Dev Disabil 2016;58:20-30.

9 Horwitz SM, Briggs-Gowan MJ, Storfer-Isser A, et al. Prevalence, correlates, and persistence of maternal depression. J Womens Health 2007;16:678-91.

10 Raphael D, Bryant T, Mikkonen J. Social determinants of health: the Canadian facts. Ontario tech university faculty of health sciences and York University school of health policy and management, 2020. Available: https://thecanadianfacts.org/The_Canadian_Facts-2nd_ed. pdf [Accessed 8 Oct 2020].

11 Berkman LF, Kawachi I, Glymour M. Social epidemiology. 2nd edn. New York: Oxford University Press, 2014.

12 Kawachi I, Kennedy BP. Income inequality and health: pathways and mechanisms. Health Serv Res 1999;34:215-27.

13 Fone D, White J, Farewell D, et al. Effect of neighbourhood deprivation and social cohesion on mental health inequality: a multilevel population-based longitudinal study. Psychol Med 2014;44:2449-60.

14 Blakely TA, Kennedy BP, Glass R, et al. What is the lag time between income inequality and health status? J Epidemiol Community Health 2000;54:318-9.

15 Zheng $\mathrm{H}$. Do people die from income inequality of a decade ago? Soc Sci Med 2012;75:36-45.

16 McLeod JD. Social Stratification and Inequality. In: Aneshensel CS, Phelan JC, Bierman A, eds. Handbook of the Sociology of Mental Health [Internet]. Dordrecht: Springer, 2013: 229-53. https://link. springer.com/chapter/

17 Coyne SM, McDaniel BT, Stockdale LA. "Do you dare to compare?" Associations between maternal social comparisons on social networking sites and parenting, mental health, and romantic relationship outcomes. Comput Human Behav 2017;70:335-40.

18 Moore G. Structural Determinants of Men's and Women's Personal Networks. Am Sociol Rev 1990;55:726.

19 Stansfeld SA. Social support and social cohesion. In: Marmot M, Wilkinson R, eds. Social determinants of health. 2nd edn. Oxford: Oxford University Press, 2005.

20 Brown GW, Andrews B, Harris T, et al. Social support, self-esteem and depression. Psychol Med 1986;16:813-31.

21 Vilhjalmsdottir A, Gardarsdottir RB, Bernburg JG, et al. Neighborhood income inequality, social capital and emotional distress among adolescents: a population-based study. J Adolesc 2016;51:92-102. 
22 Erdem Özcan, Van Lenthe FJ, Burdorf A. Income inequality and psychological distress at neighbourhood and municipality level: an analysis in the Netherlands. Health Place 2019;56:1-8.

23 Quon EC, McGrath JJ. Community, family, and subjective socioeconomic status: relative status and adolescent health. Health Psychol 2015;34:591-601.

24 Ahern J, Galea S. Social context and depression after a disaster: the role of income inequality. $J$ Epidemiol Community Health 2006;60:766-70.

25 Pabayo R, Dunn EC, Gilman SE, et al. Income inequality within urban settings and depressive symptoms among adolescents. J Epidemiol Community Health 2016;70:997-1003.

26 Vilhjalmsdottir A, Bernburg JG, Gardarsdottir RB, et al. Community income inequality and adolescent emotional problems: a populationbased study. J Community Psychol 2018;46:715-33.

27 Vilhjalmsdottir A, De Clercq B, Gardarsdottir RB, et al. Decreasing income inequality and adolescent emotional distress: a populationbased case study of Icelandic adolescents 2006-2016. Int J Public Health 2019;64:253-63.

28 Gresenz CR, Sturm R, Tang L. Income and mental health: unraveling community and individual level relationships. J Ment Health Policy Econ 2001;4:197-203.

29 McLaughlin KA, Costello EJ, Leblanc W, et al. Socioeconomic status and adolescent mental disorders. Am J Public Health 2012;102:1742-50.

30 Fujita M, Nagashima K, Takahashi S, et al. Inequality within a community at the neighborhood level and the incidence of mood disorders in Japan: a multilevel analysis. Soc Psychiatry Psychiatr Epidemiol 2019;54:1125-31.

31 Kahn RS, Wise PH, Kennedy BP, et al. State income inequality, household income, and maternal mental and physical health: cross sectional national survey. BMJ 2000;321:1311-5.

32 Karagiannaki E. The empirical relationship between income poverty and income inequality in rich and middle income countries. centre for analysis of social exclusion, London school of economics and political science, 2017. Available: https://pdfs.semanticscholar. org/c131/438853db6dadc35dda1921207eeb2dffd22e.pdf?_ga= 2.161078142.2131827670.1596235935-166538876.1596235935 [Accessed 11 Jan 2021].

33 McDonald SW, Lyon AW, Benzies KM, et al. The all our babies pregnancy cohort: design, methods, and participant characteristics. BMC Pregnancy Childbirth 2013;13 Suppl 1:S2.

34 Tough SC, McDonald SW, Collisson BA, et al. Cohort profile: the all our babies pregnancy cohort (AOB). Int J Epidemiol 2017;46:1389-90.

35 Julian LJ. Measures of anxiety: State-Trait anxiety inventory (STAI), Beck anxiety inventory (BAl), and hospital anxiety and depression Scale-Anxiety (HADS-A). Arthritis Care Res 2011;63:S467-72.

36 Cox JL, Holden JM, Sagovsky R. Detection of postnatal depression. development of the 10-item Edinburgh postnatal depression scale. Br J Psychiatry 1987:150:782-6.

37 Statistics Canada (StatCan). Dissemination area: detailed definition. statistics Canada, 2018. Available: https://www150.statcan.gc.ca/ n1/pub/92-195-x/2011001/geo/da-ad/def-eng.htm [Accessed 11 Jan 2021].
38 City of Calgary. Past census results 2015 census results book. city of Calgary, 2015. Available: https://www.calgary.ca/ca/city-clerks/ election-and-information-services/civic-census/censusresults.html [Accessed 11 Jan 2021].

39 von Hippel P, Hunter D, Drown M. Better estimates from binned income data: interpolated CDFs and mean-matching. Sociol Sci 2017;4:641-55.

40 Statistics Canada (StatCan). 2006 census of population. statistics Canada, 2006. Available: https://www12.statcan.gc.ca/censusrecensement/2006/index-eng.cfm [Accessed 11 Jan 2021].

41 Statistics Canada (StatCan). Low income cut-offs. [cited 2021 Jan 29], 2015. Available: https://www150.statcan.gc.ca/n1/pub/ $75 f 0002 \mathrm{~m} / 2009002 / \mathrm{s} 2-$ eng.htm

42 Dennis C-L. Can we identify mothers at risk for postpartum depression in the immediate postpartum period using the Edinburgh postnatal depression scale? J Affect Disord 2004;78:163-9.

43 Radloff LS. The CES-D scale: a self-report depression scale for research in the general population. Appl Psychol Meas 1977;1:385-401.

44 Moeller J. A word on standardization in longitudinal studies: don't. Front Psychol 2015;6:1389.

45 Coates R, Ayers S, de Visser R. Factor structure of the Edinburgh postnatal depression scale in a population-based sample. Psychol Assess 2017;29:1016-27.

46 Locascio JJ, Atri A. An overview of longitudinal data analysis methods for neurological research. Dement Geriatr Cogn Dis Extra 2011;1:330-57.

47 Secondary Analysis to Generate Evidence (SAGE) Team. Accessing data. PolicyWise for Children \& Families, 2017. Available: https:// policywise.com/sage/accessing-data/ [Accessed 11 Jan 2021].

48 Statistics Canada (StatCan). Table 11-10-0134-01 Gini coefficients of adjusted market, total and after-tax income, 2020. Available: https:// doi.org/10.25318/1110013401-eng [Accessed 11 Jan 2021]

49 Horwath E, Johnson J, Klerman GL, et al. What are the public health implications of subclinical depressive symptoms? Psychiatr $Q$ 1994;65:323-37.

50 Rose G. Sick individuals and sick populations. Int J Epidemiol 1985;14:32-8.

51 Quon EC, McGrath JJ. Province-level income inequality and health outcomes in Canadian adolescents. $J$ Pediatr Psychol 2015;40:251-61.

52 Lancaster CA, Gold KJ, Flynn HA, et al. Risk factors for depressive symptoms during pregnancy: a systematic review. Am J Obstet Gynecol 2010;202:5-14.

53 Almeida V. Income inequality and redistribution in the aftermath of the 2007-2008 crisis. Natl Tax J 2020;73:77-114

54 Wang J, Smailes E, Sareen J, et al. The prevalence of mental disorders in the working population over the period of global economic crisis. Can J Psychiatry 2010;55:598-605.

55 Frasquilho D, Matos MG, Salonna F, et al. Mental health outcomes in times of economic recession: a systematic literature review. BMC Public Health 2016;16:115. 